RHS. Revista. Humanismo. Soc. 6(1): 32-48, 2018

\section{El populismo como un concepto complejo: un reto para las definiciones clásicas ${ }^{1}$}

de investigación

\author{
Laura Toro Arenas ${ }^{2}$ \\ laura.toroa@udea.edu.co
}

https://doi.org/10.22209/rhs.v6n1a04

Recibido: diciembre 12 de 2017.

Aceptado: mayo 5 de 2018.

\section{Resumen}

En este artículo se ofrece una respuesta a la pregunta por las causas de la dificultad para encontrar un consenso respecto de cuáles fenómenos son populistas y cuáles no. Se afirma que el populismo es un concepto esencialmente polémico (Gallie, 1998) al tiempo que agrupa fenómenos dispares desde una concepción específica de la soberanía popular dentro de la narrativa democrática, respecto de la cual existen disputas interminables. También se propone que para considerar el populismo reconociendo estos elementos se hace preciso vincular la naturaleza normativa del mismo, puesto que, las definiciones clásicas dadas al respecto son insuficientes en vista de que no consideran este componente, cuya aceptación excluye la posibilidad de solucionar definitivamente el problema de la

1| Este artículo es producto de una práctica investigativa realizada en la Escuela de Humanidades de la Universidad EAFIT durante el primer semestre del año 2017.

2| Universidad EAFIT, estudiante de Ciencias Políticas. Universidad de Antioquia, estudiante de Filosofía. Medellín, Colombia. categorización clásica de un fenómeno como populista o no populista. Se usa una metodología cualitativa de revisión conceptual, donde se revisa tanto el ejercicio propuesto por Gallie de los conceptos esencialmente polémicos como también algunas anotaciones de Connolly (1993) sobre la conceptualización de lo normativo en ciencias sociales.

Palabras clave: comunicación política, democracia, juicio de valor, conceptualización, concepto esencialmente polémico, categorización, discurso, política.

\section{Abstract}

An answer is proposed in this paper as to why it is hard to find consensus on which phenomena are considered as populist and which are not. It is argued that populism is an essentially contested concept (Gallie, 1998), which encompasses disparate phenomena from a particular notion of popular sovereignty within the democratic narrative, around which there are endless disputes. It is also proposed that in order to analyze populism taking into account these elements, it is necessary to acknowledge its normative nature, since classical definitions of populism fall short by not considering this component, the acknowledgement of which excludes the possibility of definitively solving the problem of the classic categorization of a phenomenon as populist or non-populist. A qualitative conceptual review methodology is used. Both the essentially contested concepts as proposed by Gallie and some insights on the 
conceptualization of the normative elements in social sciences by Connolly (1993) are addressed.

Keywords: Political communication, democracy, value judgment, conceptualization, essentially contested concept, categorization, discourse, politics.

\section{Introducción}

e I populismo como categoría política experimenta una reciente proliferación de definiciones que se soporta tanto en la antigüedad de la palabra como en la sombra conceptual de los fenómenos prototípicamente llamados populistas. De cualquier manera, el uso extensivo del concepto ha llevado a que una serie de prácticas, estilos y discursos (Fairclough y Fairclough, 2012) muy diversos entre sí sean señalados como populistas. Este uso ha permitido que el populismo se constituya en una categoría confusa, amplia y esquiva que carece de representantes significativos que se tilden a sí mismos como tales, pretendiendo reivindicar su pertenencia a un esquema ideológico que defina los lineamientos doctrinales populistas (Melo, 2014).

El objetivo esencial de este artículo es reseñar la existencia de un rasgo dentro del populismo, según el cual este posee un eje exclusivamente normativo. ${ }^{3}$ En el marco de esto se explica que la manera en que en la práctica se utiliza el concepto de populismo no puede ser entendida a través

3| Casi todos los conceptos en ciencias sociales podrían ser expuestos como conceptos esencialmente polémicos y esencialmente normativos. La diferencia sobre la que se llama la atención es que en el caso del populismo el ser una consideración negativa de un fenómeno es lo único que la diferencia de otras categorías. En otros conceptos, tales como el liberalismo o conservadurismo, además de la apreciación normativa implícita, existen rasgos que los separan de otras categorías similares. de una conceptualización rígida tanto en intensión como en extensión (clásica) del concepto de populismo. Dicha derivación de este propósito, a su vez, se vale de la idea de que el populismo es un concepto esencialmente polémico y ello constituye un marco teórico razonable para estudiarlo, y que, a diferencia de otros conceptos esencialmente polémicos en ciencias sociales, no tiene fuera de su eje normativo ninguna otra característica que lo separe de categorías cercanas como el paternalismo y el caudillismo. Para probar esto, se revisan las conceptualizaciones del populismo, se exponen sus limitaciones, se muestra que dichas aproximaciones no explican adecuadamente el uso del concepto, se describen ciertas particularidades de su uso y luego se sigue, en una parte del documento, la metodología de análisis de los conceptos esencialmente polémicos. Este es un estudio de caso conceptual y de tipo explicativo y de nivel comprensión. Se concluye que la naturaleza conceptual del populismo impide que este se diferencie de sus categorías cercanas si no es con base en un eje exclusivamente normativo y que esto, a su vez, imposibilita la construcción clásica del concepto de populismo.

\section{El populismo comprendido en términos clásicos}

La literatura sobre el populismo es enfática en responder a la pregunta por su definición. En este apartado, una vez revisada una parte de la literatura disponible sobre el populismo, se agruparon las diferentes respuestas a la pregunta ¿qué es populismo? alrededor de tres tipos de definiciones. Todos los autores revisados coinciden en señalar que en el populismo se da una oposición entre pueblo y élite con tono polarizante y una narrativa con figuras homogéneas. 
La primera agrupación de definiciones señala que el populismo es un fenómeno político, en el que además de reivindicarse a los marginados a partir de la polarización entre pueblo y élite, la figura del pueblo es esencial, aunque difusa. Los exponentes más emblemáticos de esta definición son Arenas (2016), Bobbio (1998), Canovan (1981), Charandeau (2009), De la Torre (2013), Green (2013), (2015), Laclau (2005), Mudde y Rovira (2017), Müller (2016), Shils (1956) y Worsley (1969). Resalta la insistencia de estos autores en que en el populismo se monopoliza la representación del pueblo.

En el segundo tipo de definición se menciona que lo fundamental respecto del populismo, además del rasgo ya mencionado, es su insistencia en la creación de la «verdadera comunidad», que es la idealización de un grupo poblacional marginado o autóctono, cuyo seguimiento y gobierno permitiría la creación o regreso de un porvenir armónico. Los autores más importantes dentro de esta categoría son: Arditi (2004), Vogel (2016), McRae (1969), Wiles (1969) y Zanatta (2014).

También existe un subgrupo que de forma paralela al anterior señala que lo definitivo para hablar de populismo radica en la popularidad y el carisma del líder populista dentro de los movimientos de masas no institucionalizados o medianamente institucionalizados, ello materializado en una forma de liderazgo directo fuertemente mediado por la exaltación de las emociones. Weyland (2001) y Berlin (1992) son representativos de este subgrupo.

En tercer lugar, se encuentra un tipo de definición que habla del populismo en términos de un modelo económico como también de una ideología política en concreto. Se identifica el populismo con la izquierda política como con políticas redistributivas. Los autores más significativos adscritos a esta postura son Dornbusch y Edwards (1990), Keiser y Álvarez (2016) y Palacios (2011). En este grupo se indica que un actor es populista en tanto sugiere o toma medidas económicas o políticas públicas inscritas a una línea doctrinal económica o social que es engañosa o ineficiente, pero que logra crear polarización en la audiencia ubicándose como el reivindicador de dicha postura y de uno de los bandos confrontados, generalmente este bando es el representado como mayoritario.

A continuación, se hace una comparación entre las diferentes conceptualizaciones presentadas en el apartado anterior, ello con el fin de encontrar si existen o no lineamientos comunes en las definiciones que permitan suponer que ellas se refieren aproximadamente al mismo fenómeno.

Las diferentes definiciones comparten, por lo menos, la idea de que en el populismo la oposición entre pueblo y élite es fundamental. En este relato de polarización el pueblo es idealizado y la élite responsabilizada por los daños al mismo. Este parece ser el criterio más importante de exclusión del concepto. Siguiendo a De La Torre (2007), esa polarización tiene un tono similar al expuesto por Schmitt como la lucha entre amigo y enemigo, donde los diferentes actores involucrados precisan, por lo menos en lo referente a la representación, de la eliminación del otro.

En las conceptualizaciones previamente descritas puede notarse que los autores no afirman que los rasgos del populismo que para ellos no son centrales sean inexistentes en el fenómeno. De hecho, parecen tratar de vincularlos al propio rasgo que para ellos sí es central. Esto puede explicarse si se nota que los autores se refieren a distintos niveles analíticos a la hora 
de definir el populismo. Es decir, cuando ellos señalan el rasgo que a su juicio es el característico del populismo frente a otras categorías, están suponiendo como central un formato específico de acción política y una forma concreta en la que se manifiesta el populismo, y por ello las otras descripciones -en tanto se refieren a otros formatos- pueden resultar incompletas.

Una de las distinciones que ayudan a abstraer los diferentes niveles analíticos en los que se encuentran los autores es la presentada por Fairclough y Fairclough (2012), quienes proponen una metodología de análisis del discurso político, donde se supone que la democracia deliberativa y el pluralismo constituyen el marco normativo ideal de la política. Allí se evalúa si el agente político efectivamente está actuando de forma compatible con los procedimientos propios de una deliberación adecuada, para lo cual introducen una diferenciación entre prácticas, estilos y discursos.

Una práctica es una acción que se sugiere en el marco de una argumentación, así como la ejecución de una acción con contenido político, en un contexto político y por un agente autorizado. Estas prácticas son institucionales, sin embargo, en este artículo se sugiere que para el estudio del populismo también se supongan como prácticas las acciones que, en virtud de su importancia, incluso sin estar en un contexto institucionalmente definido como político, son políticas.

Un ejemplo del enfoque en las acciones en el estudio del populismo se encuentra en Wiles (1969), quien resalta la práctica común en los líderes populistas de suprimir los cuerpos legislativos.

Por otro lado, el discurso constituye la argumentación y la estructura de la misma orientada a la acción, donde se exponen los fines, circunstancias y valores que justifican un actuar. Un ejemplo de una conceptualización del populismo en términos discursivos es la ofrecida por Charandeau (2009), quien define el populismo como una estrategia discursiva que «exagera» los recursos democráticos, a través de la polarización.

El estilo es el modo en que se presenta el actor político, a través de elementos en principio indirectos. Esta conceptualización de estilo se basa también en el trabajo de Wodak (2009) respecto de las dimensiones políticas que es retomado por Fairclough y Fairclough (2012). Allí se mencionan aspectos como el carisma, la credibilidad y la actuación de los agentes políticos como dimensiones relevantes de la política. De hecho, estas condiciones de liderazgo junto con una relación no institucionalizada del pueblo con el líder es el rasgo central que Weyland (2001) utiliza para definir el populismo.

En otro sentido, hay una diferenciación entre régimen político y movimiento político que igualmente es útil. El primero de ellos alude a aquellos fenómenos que son esquemas políticos con prácticas gubernamentales históricas, de modo que logran una definición más específica. Por otra parte, el segundo tipo de suceso no está necesariamente expuesto en un régimen y en tanto ello no ocurre no está involucrado en prácticas gubernamentales que le añadan otras características tales como el clientelismo o el quiebre institucional. Esta aproximación es más amplia.

Un ejemplo del primer tipo es el trabajo de Steven Levitsky y James Loxton (2013), quienes aseveran que los populistas son personajes fuera de la política parlamentaria del pacto, que pretenden refundar la patria, que una vez en el poder combaten los mecanismos de control y ejecutan medidas autoritarias. 
El trabajo de Müller (2016) es un ejemplo del populismo como movimiento político, pues él define rasgos generales del mismo que se refieren a un tipo ideal de populismo no necesariamente identificable con un régimen político y sus prácticas.

No obstante, la anterior diferenciación tampoco resuelve el problema de la conceptualización ni categorización de casos como ejemplos de populismo, pues solo expone que la palabra es adjudicada a fenómenos que están enmarcados en diversos niveles analíticos y con ello documenta de nuevo que el populismo es presa de gran ambigüedad conceptual.

Cabe anotar que es una tendencia que los autores dediquen una parte importante de su documento a exponer las razones por las cuales ciertos actores no han de ser tildados como populistas mientras otros sí lo deberían ser, para ello ofrecen las mismas razones, pero concluyen juicios distintos. Esto parece mostrar que la polémica en los autores se ocasiona una vez la definición de populismo es aplicada, porque es en este punto que los conceptos involucrados en la definición están descritos en términos tan amplios que hacen difícil el acuerdo para categorizar los fenómenos. La polémica no se refiere tanto a la definición del concepto como al uso del mismo.

La atención que el populismo ha obtenido también ha generado la sensación de que existen una serie de fenómenos caracterizados por sí mismos como populistas de forma atemporal. Sin embargo, esa sólida representación de supuestos casos prototípicos ha impedido vislumbrar la también frecuente polémica que esos mismos casos generan una vez se juzgan como populistas frente a aquellos que son adeptos a dichos fenómenos y sus postulados. Llama la atención que frecuentemente ese desacuerdo no tenga que ver con que una de las partes sostenga que el populismo no es una categoría válida, sino que, a pesar de contar con el reconocimiento de la validez de la categoría por parte de todos los usos rivales, existe la convicción en algunos de ellos de que la categoría de populista no aplica al caso del que se está discutiendo, mientras otros usos rivales señalan que sí aplica.

Puede concluirse que la revisión de literatura indica la ausencia de un acuerdo claro respecto del significado del populismo; sin embargo, no sugiere tampoco que no exista un modelo común al que, en general, las diferentes conceptualizaciones traten de acercarse. También propone que la categorización de un fenómeno como populista está dada especialmente por la normatividad que se aplica al fenómeno y no por rasgos identificables por cualquier analista.

\section{Insuficiencias y problemas epistemológicos de las definiciones clásicas de populismo}

En las conceptualizaciones ya presentadas de populismo se encontraron cuatro dificultades. Estos problemas pueden hallarse también en otros conceptos políticos, pero en el caso del populismo afectan especialmente la formulación de su definición, pues en ellas parece agotarse el sentido del concepto.

Los siguientes rasgos son problemáticos dentro de las definiciones ya reseñadas en relación a lo que dichas definiciones pretenden lograr, no en sí mismos. Es decir, las definiciones previamente reseñadas coincidían en su 
objetivo de establecer límites claros tanto en intensión como en extensión dentro de la categoría de populismo y, por ello, una parte de los rasgos que serán enumerados a continuación son problemáticos porque impiden lograr que dichas definiciones sean excluyentes con otras en intensión y extensión, no porque la existencia de estos rasgos en sí misma sea un problema para una caracterización de un fenómeno, sino porque lo es para una definición que espera evitar la polémica en la categorización de los fenómenos.

La no existencia de un consenso. En las definiciones de populismo que se señala el carácter, por ejemplo, «irresponsable» del mismo, se ignora que no existe consenso en lo correspondiente al hecho de qué es una política irresponsable, inviable o engañosa. Estas son decisiones de corte económico o social respecto de políticas públicas concretas cuya validez es constante objeto de polémica. Tal es el caso del proteccionismo y la apuesta por la nacionalización de compañías como sinónimo de populismo.

Lo anterior es problemático, porque el populismo podría convertirse en un concepto absolutamente normativo con poco peso analítico. Lo problemático de este punto no radica en la existencia de una valoración implícita, sino en la ausencia de otro criterio alrededor del cual se agrupen estos fenómenos, pues si se sigue esta línea de análisis el populismo no parecería ser nada más que manipulación de masas como consecuencia de la adherencia a una política específica que, además, otro analista puede considerar auténticamente válida e inteligente. Con esta aproximación el concepto pierde capacidad explicativa y, eventualmente, puede constituir exclusivamente una forma peyorativa de señalar un fenómeno que con otra palabra sería explicado con mayor claridad. Ello no es un problema, lo que sí constituye un reto para las ciencias sociales es renunciar a la pretensión de construir una definición de populismo que ignora sistemáticamente este rasgo.

\section{Insuficiencia de la polarización entre la élite y el pueblo. La mera alusión al pueblo como aquel} en nombre de quien se habla es insuficiente para definir el populismo, puesto que el pueblo es una premisa básica de los modelos democráticos. Casi cualquier fenómeno político podría fácilmente caer en el apelativo de populista, en tanto justifica su legitimidad en el pueblo.

Pitkin (1972) también expone que la alusión a la figura del pueblo es insuficiente para definir al populismo, debido a que las democracias y eventualmente el fascismo también soportan su legitimidad en la misma figura. En el populismo no hay una alusión a la figura del pueblo en el mismo sentido que la hay en otros esquemas democráticos, tales como los liberales, donde el pueblo es una figura heterogénea basada en el individuo y con pocas identidades colectivas que lo supriman.

La mayoría de autores revisados sostienen que lo que caracteriza al pueblo del populismo es que en este se trata del relato de una comunidad unificada y homogénea, sin embargo, ese relato de pueblo también tiene roces importantes con otros fenómenos. Es necesario revisar si las definiciones de este tipo logran diferenciar el pueblo del populismo del pueblo de otros fenómenos como el caudillismo, el fascismo y el autoritarismo y si lo que acá se señala como populismo no corresponde realmente a un tipo de instrumentación discursiva de los valores democráticos presentes en muchos, pero señalados en pocos. 
Falta de continuidad. No hay necesariamente una continuidad discursiva, práctica o estilística de rasgos populistas en los fenómenos que se tildan de populistas. En otras palabras, las definiciones encontradas de populismo indican características cuya materialización no es constante ni representa la totalidad de un programa político, campaña, o gobierno. Por ejemplo, en el caso de Perón, si bien sí hay un relativo consenso ${ }^{4}$ respecto de su condición de fenómeno populista, hay ocasiones donde lo que dice o hace parece ser populista de acuerdo con muchas definiciones de las revisadas, sin embargo, ello no es el grueso de su política, ni siquiera de su discurso. Es necesario definir qué tanta presencia han de tener estos rasgos para hablar de populismo.

Otra alternativa con la que se puede solucionar la limitación de la continuidad es señalar que existen enunciados dentro de un discurso, prácticas y estilos lo suficientemente definitivos para un gobierno, campaña o estilo político que hacen inevitable que el resto del fenómeno no esté orientado por ello. No obstante, en este punto se hacen difusos los criterios con los que tal afirmación podría hacerse.

Maleabilidad en la descripción. En los trabajos referentes a la conceptualización del populismo, antes de señalar que un fenómeno es populista, se suele caracterizar con independencia de ese adjetivo al fenómeno mismo. Esa descripción es determinante para definir si este cumple o no las condiciones de populismo, más allá de los criterios mismos de categorización, pues la descripción trae un juicio implícito que otro analista podría

4| Buela (2007) podría ser un caso de oposición a esta afirmación, sin embargo, su caracterización es más una ampliación de las implicaciones del peronismo que una negación de su pertenencia al tipo de fenómenos prototípicamente llamados populistas. no realizar. En el caso del populismo esto es especialmente importante, pues este concepto implica categorías cuya evaluación es abiertamente subjetiva, tales como justicia social, participación popular, pueblo, democracia entre otros.

Igualmente, es común indicar que el populismo solo exaspera las emociones. Sin embargo, cualquier manifestación política implica emociones que pueden ser instrumentalizadas de múltiples formas. Por consiguiente, el uso de emociones no es criterio suficiente para calificar una aproximación política, pues en la práctica, a la hora de clasificar acciones, es difusa la barrera entre las emociones y la política «racional».

Con base en esto puede aseverarse que las definiciones clásicas del populismo cuentan con una serie de retos importantes a nivel de formulación conceptual para la construcción de una definición del populismo que sea coherente con sus fines en términos de extensión e intensión. La pregunta entonces radica en saber qué tan importantes son estas limitaciones en el caso concreto del populismo como concepto.

\section{El rasgo especial del}

\section{populismo como concepto}

A continuación, se exponen algunas características del populismo que están derivadas de su carácter esencialmente normativo. Así como se muestra de forma más concreta en qué consiste dicha normatividad esencial.

Muchos de los usos del concepto de populismo son aplicaciones en contextos específicos de una definición difusa del mismo. Tal es el caso de las definiciones que hablan del populismo como una política irresponsable, polarizante 
o manipuladora de masas (Álvarez y Kaiser, 2016). Estas definiciones dejan campo abierto para las diversas acepciones de lo responsable, lo polarizante y lo manipulador.

Conolly (1993) afirma que existen una serie de conceptos (cluster concepts) en las ciencias sociales cuya descripción implica su ubicación en un contexto teórico más amplio, de tal modo que un concepto descriptivo implica a su vez un posicionamiento normativo del mismo respecto de un esquema teórico que lo abarque. En este sentido, cuando se describe un fenómeno utilizando ciertos conceptos es preciso que se exponga el significado concreto de cada uno de los conceptos intervinientes y el marco teórico en el que se ubican, porque si su definición se limita exclusivamente a la fórmula lingüística que señalan, se da entrada a la polémica respecto de su uso. Esto último en tanto las categorías que se utilizan para definir el concepto suponen a su vez aceptar otra serie de categorías, de las cuales hay fuertes debates respecto del «modo correcto de uso».

El populismo puede ser uno de estos conceptos, pues en la práctica se indica implícitamente que este es una forma desviada de interpretar la soberanía popular de la democracia (Charaudeau, 2009), ya que allí se alude a un pueblo no plural e iliberal como aquel que ha de reclamar el poder, mientras se asume que lo auténticamente democrático es, por ejemplo, la alusión a un pueblo plural y liberal. Para sostener qué es específicamente una forma desviada de este componente de la democracia es preciso aceptar un eje normativo, donde se admita como errónea una aproximación a la soberanía popular de la democracia que se aleje de ese formato.

Esto se soporta en que, una postura común en los autores revisados consiste en señalar que el pueblo del populismo es excluyente y supone un cuerpo homogéneo que se opone al resto de la población, lo que a su vez compite con la visión liberal del pueblo. Sin embargo, ambas posturas son posicionamientos normativos que están en la base de cada una de las argumentaciones. Las definiciones que se hacen del populismo tienden a presentar como necesaria una condición que no lo es y que de hecho funciona como mecanismo teórico enmarcado dentro una tradición en específico más que de un concepto independiente de dichas valoraciones.

Es por lo anterior que el populismo, como concepto, reúne un grupo de fenómenos con criterio a un eje normativo. Ahora, si se asume una postura en específico frente a esos conceptos conexos, tales como voluntad popular, justicia social y participación, se puede entonces afirmar que (desde esa posición) alguien es o no es populista.

Conolly (1993) expone que muchos conceptos con los que se describe el mundo político solo tienen sentido desde una perspectiva moral. Al señalar esto, asevera que dicho concepto solo podría agruparse bajo un rótulo en específico si se comparte una posición moral al respecto.

En el caso de los fenómenos tildados de populistas el rótulo que justifica su agrupación se genera por una visión específica de la democracia que define el marco normativo en el que tiene lugar el concepto. En otras palabras, la categoría populismo se diferencia de la democracia por las consideraciones morales que hacen posible la clasificación de los fenómenos en esa categoría. Tanto el populismo como la democracia suponen un componente normativo de entrada. La diferencia radica en el juicio moral, pero bien puede ser que el mismo fenómeno sea para algunos auténticamente democrático como para otros populista. 
Es precisamente dicha complejidad valorativa la que posibilita, en parte, la polémica en los usos y categorización de los casos, así como en la definición del concepto. Lo anterior puede verse en la práctica en el uso del rótulo de populista, pues cuando se dice que alguien es populista se señala que está diciendo representar a un pueblo (que se supone ficticio), a favor de unas metas (que se consideran imposibles o ambiguas), por medio de unos métodos (que se creen insuficientes o contraproducentes) y con una popularidad producto del engaño emocional. Si se apoya el contenido concreto de una propuesta política de un formato similar esta no se tilda de populista, sino de democrática.

Un ejemplo de la aplicación implícitamente normativa del populismo está expresado en la propuesta de Hermet (2003), quien comenta que, en el populismo, en un afán clientelista por lograr satisfacer las demandas difusas y emocionales del pueblo, rápidamente se suprime «la realidad» de los tiempos políticos; es decir, se toman medidas irresponsables, imprudentes y se actúa esencialmente por convicción. Este uso del concepto de populismo es subjetivo y vago, pero ello no limita el hecho de que haga parte importante de otros usos del mismo, incluso parece ser que sin esta consideración implícita los otros usos del término no podrían sino ser sinónimos de nacionalismo, clientelismo o caudillismo maniqueo, pues como ya se expuso, la figura del pueblo es insuficiente.

En una parte importante de los usos del populismo parece estar sobrentendida la idea de que este se encuentra a medio camino entre la democracia y el autoritarismo, pero la democracia en sí misma no señala unos parámetros comportamentales claros, pues la composición de esos parámetros en específico depende de un marco teórico más amplio donde el analista inscriba los valores democráticos.
Asumir lo anterior implica que ni el liberalismo, el pluralismo o las garantías sociales son inherentes al concepto de democracia, pues la idea misma del poder del pueblo es difusa y se somete a diversas interpretaciones de lo que es el pueblo y los canales para materializar su poder. En este sentido, el populismo se aleja de la democracia de corte liberal, pero no de los valores difusos de la misma que, de hecho, reivindica.

Se puede afirmar que el populismo como rótulo significa la aplicación engañosa de lo que se asume que es la correcta acepción de la soberanía popular en la «verdadera democracia», en tanto se enfoca demasiado y lo hace incorrectamente en el componente de la soberanía popular. ${ }^{5}$

La anterior conclusión es importante en tanto sugiere que el populismo como concepto está compuesto de tal forma que las categorías del mismo, con base en las cuales se puede elaborar un ejercicio de discriminación conceptual, son en sí mismas normativas y esta consideración no puede separarse de la formulación del concepto, incluso si ello supone abandonar el esfuerzo por garantizar una categorización homogénea de un fenómeno como populista.

\section{Descripción de Gallie de}

los conceptos esencialmente polémicos y su aplicación al concepto del populismo

La propuesta de Gallie (1998) de los conceptos esencialmente polémicos señala que estos son

5| Esto asumiendo que la democracia también constituye un concepto difuso y con múltiples interpretaciones. Sin embargo, en este artículo no se profundiza en el carácter conceptual de la democracia. 
conceptos respecto de los cuales hay discusiones que parecen infinitas y aun así razonables en lo relativo a la categorización de un caso como un ejemplo de ese concepto.

Las condiciones para que un concepto sea esencialmente polémico son las siguientes:

(I) Debe ser evaluativo en el sentido de que significa 0 acredita algún tipo de logro valorado. (II) Este logro debe tener un carácter internamente complejo, pues su valor le es atribuido como un todo. (III) Cualquier explicación de su valor debe, por lo tanto, incluir referencias a las respectivas contribuciones de sus diversos aspectos o partes; aun cuando haya nada absurdo o contradictorio en ninguna de las distintas descripciones rivales posibles de su valor total, una de las cuales coloca sus partes 0 aspectos componentes en un orden de importancia, una segunda los coloca en un segundo orden y así sucesivamente. En resumen, el logro acreditado se puede describir inicialmente de varios modos. (IV) El logro acreditado debe ser de un tipo que admita una modificación considerable a la luz de las circunstancias cambiantes; y tal modificación no puede prescribirse ni predecirse por adelantado. Por conveniencia, al concepto de cualquier logro de este tipo lo llamaré de carácter «abierto» [...] (V) Cada grupo reconoce el hecho de que su propio uso es impugnado por los de otros grupos, y que cada grupo debe tener por lo menos alguna apreciación de los diferentes criterios a la luz de los cuales los otros grupos afirman que están aplicando el concepto en cuestión. En términos más simples usar un concepto esencialmente impugnado significa usarlo tanto agresiva como defensivamente (Gallie, 1998, p. 10-12).

Adicional a estas, Gallie (1998) reseña otras dos condiciones que son las que definen si se justifica continuar el uso del concepto esencialmente polémico. Estas condiciones son: (VI) El concepto es derivado de un modelo original que es imitado por los otros y respecto del cual se reconoce su autoridad por todos los rivales dentro de la polémica y (VII) Es probable que la competencia continua por el reconocimiento del logro entre los diferentes rivales del concepto permita que el logro original sea mantenido de forma óptima.

La primera condición señala que el concepto debe significar la obtención de un logro, en el sentido de que ese concepto implica un rótulo de carácter valorativo sobre ese objeto que se evalúa. Un ejemplo presentado por Gallie es el de ser democrático. La segunda condición indica que ese mismo logro (por ejemplo, la democracia) debe tener muchos elementos dentro de sí cuya definición específica y valoración sea compleja y en ese sentido cuente con variadas interpretaciones. La tercera condición exige que ese logro, que es valorativo y complejo precise, para asignársele a un objeto, de una revisión de los diferentes componentes del mismo. De esta manera, por ejemplo, la democracia como logro puede asignársele a un objeto alegando diferentes elementos que hacen parte de su composición y la alusión a esos componentes por parte de diferentes jueces no implica que ellos lleguen a la misma conclusión, pues esos elementos son también objeto de polémica. La cuarta condición es el carácter abierto del logro, es decir, ese rótulo obtenido -la democracia- puede ser recibido en otras circunstancias como también retirado, pues su composición interna es tan compleja, ambigua y difusa que puede dejar de serle propia al objeto o situación al que se le designa y pertenecerle a otro que lo «poseía» de forma latente. La quinta condición indica que los diferentes usuarios de la polémica reconocen la existencia de otros usos 
del concepto y, en ese sentido, conocen que su propio uso es disputado. En la democracia, se trata fundamentalmente de reconocer la existencia de visiones alternativas de la misma, tales como las plebiscitarias, liberales entre otras.

Las otras dos condiciones están diseñadas pensando en una situación donde no esté claro que realmente los diferentes usuarios involucrados en la polémica se refieran al mismo concepto. Es decir, es posible que la polémica exista en parte porque los usuarios se están refiriendo con la misma palabra a conceptos distintos. Por eso, Gallie demanda como condición adicional que exista un modelo común autorizado que sea perseguido por todas las aproximaciones. En el caso de la democracia, Gallie cita las tendencias que buscan eliminar las desigualdades como modelo imitado por los usos rivales. La segunda condición adicional tiene un carácter práctico y se pregunta si es útil la polémica para alcanzar el logro, o si por el contrario las posiciones rivales desembocan en situaciones donde no pueda cumplirse el logro a cabalidad.

Los conceptos como el populismo obligan a asumir cierta ambigüedad en la categorización, y de suprimirse esa ambigüedad parece que se pierde el sentido de agrupar los fenómenos bajo la misma palabra, pues estos serían descritos de mejor forma con otras categorías.

Con este apartado se presentó el mecanismo conceptual desde el que puede comprenderse el concepto de populismo y con el que se puede vincular el carácter normativo del mismo.

A la hora de revisar el populismo a la luz de las categorías de Gallie hay que anotar que su teoría describe el fin que persigue el supuesto concepto esencialmente polémico en términos positivos, mientras, en este caso cuando se tilda a un fenómeno como populista no es claro que se diga que el modelo que este imita sea una meta positiva, puede también ser una meta negativa (Zaibert y Smith, 2010).

I) Primera condición: el populismo (que solo es nombrado de esta forma por alguien exógeno al fenómeno) tiene como modelo a imitar ser una interpretación «errónea» de la democracia que sobrestima el componente de la soberanía popular. Ese logro está estructurado como el fenómeno en el que un actor gana popularidad creando una narrativa en la que se polariza el pueblo y la élite a partir de la simplificación de la realidad y dicho actor se presenta a sí mismo como el que reclama ser el vocero del pueblo.

En esta narrativa el pueblo es presentado de forma homogénea, lo que implica decir las cosas de tal forma que parecen ser conflictos irresolubles entre los intereses del pueblo y los de la élite. El carácter evaluativo de este concepto radica en la ausencia de criterios específicos a la hora de suponer una interpretación específica de la soberanía popular.

II) Segunda condición: el populismo es internamente complejo en tanto los componentes de ese modelo son a su vez dependientes de otros conceptos. No hay un acuerdo respecto de la acepción específica que tienen las categorías que están con frecuencia involucradas en su definición, tales como el pueblo, la élite, la soberanía popular, la voluntad popular o la justicia social. En consecuencia, dicho fenómeno puede ser descrito utilizando estas categorías con distinta importancia y sentido a la hora de emitir el juicio respecto de que un caso sea o no sea populista; todo esto incluso considerando que se estuviera de acuerdo en la forma lingüística con la que se define el concepto. 
Para definir populismo, autores como Mudde y Rovira (2017) resaltan el rol de la polarización entre pueblo y élite a través de distintas ideologías huéspedes, pero incluso allí es preciso revisar qué se entiende por pueblo y en qué se diferencia esa acepción en específico del pueblo de otros relatos políticos y, si bien expresan que este pueblo es homogéneo y no plural, ello en la práctica tampoco evita la polémica para la categorización de los fenómenos. Otro ejemplo es la definición de Müller (2016) de populismo, donde el aspecto central es que este monopoliza la representación del pueblo. Igualmente, Zanatta (2014) dice que el pueblo es la figura central del populismo y se caracteriza por ser monolítico y estar ante una amenaza inminente, así como por ser fuertemente comunitario. Estas descripciones mencionan con diferente importancia los mismos aspectos vinculados a la definición formal de populismo.

III) Tercera condición: la emisión del juicio respecto de que un actor es populista se refiere a las diversas partes de la descripción. Aseverar que alguien es populista implica asumir una posición específica respecto de cada una de las partes de la descripción formal del concepto. Esto último involucra entonces señalar cómo se exagera la soberanía popular, cómo se entiende la democracia, qué sentido específico tiene el pueblo y la élite, así como la forma en que se manifiesta esa relación como para lograr que dicho caso sea merecedor del rótulo de populista.

IV) Cuarta condición: el modelo de exagerar y malinterpretar el componente de la soberanía popular en la democracia mediante una polarización entre élite y pueblo, donde un actor se reclama como el vocero de la voluntad popular, es necesariamente vago en tanto no puede preverse que en otras circunstancias un fenómeno no considerado actualmente como populista obtenga el rótulo de populista, con miras a que ello existe en él de forma latente.

Ahora, esa ambigüedad se puede explicar afirmando que el lenguaje del populismo puede confundirse con el lenguaje democrático, y la forma específica que toma el populismo implica valoraciones vagas respecto de cuando se incluye más de lo que se excluye en la figura del pueblo, como también de las situaciones en las que se habla de popularidad populista producto de la emoción y no de popularidad de otro tipo, por ejemplo, producto de los intereses individuales. Incluso si dichas políticas fuesen absurdas y solo aceptables a través de la manipulación carismática es preciso llegar a un acuerdo respecto de qué es absurdo.

Hablar de populismo implica un juicio sobre la realidad política. Es como consecuencia de este primer diagnóstico a la hora de usar el concepto que se puede decir que en otra ocasión las condiciones pueden hacer parecer que las características que se vieron como definitorias para asignar el rótulo de populista a algún fenómeno parezcan evidentes en otros actores que antes no había sido tildados como tales.

v) Quinta condición: los diferentes autores reconocen que existen usos disputados del rótulo de populismo y ellos asumen que su uso es el mejor, así como consideran que los otros usos no «captan» el sentido real del término. Lo anterior puede deberse a que una vez estos autores utilizan en sus definiciones de populismo criterios de evaluación tales como justicia social, monopolización de la figura del pueblo, voluntad general, entre otros, se remiten a discusiones sobre el verdadero sentido de ellos. Es en este punto que se hace evidente que el 
populismo en la práctica funciona como un mecanismo de deslegitimación de algunas formas de democracia.

VI) Sexta condición: respecto de si la palabra populismo se refiere a un mismo concepto o a una confusión donde realmente se están nombrando fenómenos distintos aludiendo a una misma palabra, hay que señalar que el modelo a seguir por el populismo parece existir, así como esta polemicidad no parece evitar el desarrollo de ese modelo. El modelo imitado por el populismo es el de una «exageración» 0 «malinterpretación iliberal» del componente de la soberanía popular en la democracia, acompañada de una polarización entre el pueblo y la élite, donde un actor se reivindica como el vocero del pueblo.

VII) Séptima condición: la pregunta sobre si el debate entre los usos rivales del populismo permite que se alcance de forma óptima el modelo que se imita es un asunto complejo, puesto que la conveniencia de la existencia del mismo no es un asunto respecto del que haya acuerdo, aunque sí lo existe sobre el modelo. La discusión por los verdaderos casos de populismo ha traído la proliferación de señalamientos a fenómenos políticos como populistas, cuando no hay criterios claros para definir tal condición. Probablemente se esté en una situación de vacuidad conceptual. El cumplimiento de esta condición es difuso.

\section{El populismo como un} concepto esencialmente

\section{$-\mathrm{y}$ especialmente- polémico}

Se ha convertido en un lugar común afirmar que algunas prácticas, estilos o discursos son esencialmente populistas. Ello se argumenta aseverando que un actor político logra popularidad a través de la manipulación del público (Keiser y Álvarez, 2016 y Cerutti, 2009). También afirmando que esa popularidad es fruto de la representación de la realidad que hace el supuesto caso de populismo, según la cual existe una oposición entre el pueblo y las élites por medio de un relato totalizante (Antón, 2015; Ortiz, 2009 y Bobbio, 1982). Se dice que el populismo, utilizando fórmulas simples, irresponsables, inviables y contraproducentes, afirma lo que las personas del común quisieran escuchar y les crea una identidad colectiva inconveniente.

La confusión se fortalece una vez se hacen notorios los diferentes puntos de encuentro que los casos normalmente llamados como populistas tienen con otros fenómenos políticos como el paternalismo, el caudillismo y el nacionalismo. Esto sugiere que existe un problema de definición del populismo en tanto su uso se prolifera sin la existencia de criterios que sean explicativos de los atributos específicos que se le imputan a algún fenómeno como para tildarlo de populista.

Al respecto de este último punto, en una buena parte de la literatura sobre populismo se ha insistido en la construcción de una definición clásica del mismo con fronteras claras tanto en intensión como en extensión. Por ejemplo, Weyland (2001) señala que el populismo debe definirse en términos clásicos y no radiales o cumulativos, pues ello solo incrementa la confusión en su uso. Es decir, si se utilizan definiciones amplias o que señalen muchas categorías se hace difícil determinar el significado de un concepto.

Sin embargo, la dificultad en construir una definición clásica de populismo reside en que allí se suprime el carácter normativo que le da sentido 
a la definición, dado que sin esto toda definición de populismo ha de parecer muy incluyente en relación a los fenómenos que se quieren describir. Es decir, la apuesta por una definición clásica de populismo ignora que no hay criterios universales respecto de los cuales una persona adepta al fenómeno que se tilda como populista pueda identificar su movimiento con dicha descripción, pues los supuestos involucrados en las definiciones clásicas solo son dicientes de ese carácter populista en un fenómeno una vez se toma una acepción específica de las categorías involucradas en la definición del concepto y se articulan normativamente.

Un ejemplo de esta situación se da con el concepto de pueblo, involucrado en casi todas las definiciones de populismo, donde este se describe en oposición a la élite. En este caso, es preciso definir qué se entiende por pueblo con miras a poder señalar la forma en que esa definición se opone a la de élite, pero una vez se define al pueblo como una figura ambigua, desarticulada, efímera, emocional o no institucionalizada, se limita la posibilidad de que otro individuo defienda un proceso que, a su juicio, es loable utilizando la misma palabra. De hecho, también se deja de lado la situación en la cual, incluso si no hay un interés en defender un proyecto, no existan coincidencias en la forma en que distintos analistas categoricen una serie de fenómenos aludiendo a los mismos sucesos.

Gerring (1997) indica que un concepto que ha servido como categoría analítica a través de contextos históricos muy variados puede llegar a «significar mucho», tanto que impide encontrar un consenso respecto de sus límites conceptuales. En consecuencia, Gerring propone que para acabar dicha incertidumbre conviene construir una definición mínima de ese tipo de conceptos, por medio de la cual se pueda diferenciar el mismo de otras categorías cercanas y, además, definir un contexto específico en el cual la categoría tenga valor.

En este texto se cree que el diagnóstico de Gerring es igualmente aplicable al populismo; sin embargo, se propone que esa pretensión de encontrar un pequeño grupo de condiciones que funcionen como definición mínima de populismo, en vez de separarlo de categorías cercanas, terminaría acercándolo más a ellas, pues el populismo ha definido una serie tan amplia de fenómenos que aquello a partir de lo cual se podría construir una definición mínima podría bien ser una característica de otro fenómeno.

El ejercicio propuesto por Gerring se justifica en tanto existe una preocupación por la categorización de los fenómenos como ejemplares o no de dicho concepto, es decir, por el uso del concepto. Sin embargo, en algunos casos ese ejercicio puede conducir a una mayor flexibilidad en el uso del término. Otro fenómeno que puede ocurrir en este contexto es que dicha característica mínima sea tan ambigua que su determinación no resuelva el problema de la categorización de distintos casos como ejemplares de la misma. La universalidad que se le exige a dicha categoría mínima obliga a reducir el escenario en el cual ella puede, en efecto, ser excluyente con otras categorías.

Puede concluirse que, con miras a reflejar la manera en que el concepto es usado, la pretensión de construir una definición clásica es insuficiente y, además, opuesta al eje normativo que hace funcional el concepto.

El hecho de que en ciencias sociales un concepto sea esencialmente polémico, o incluso que dentro de su caracterización se encuentre 
que una parte importante del mismo es normativa, es una situación común que en sí misma no imposibilita la construcción de categorías claras al respecto, aun cuando ello traiga problemas importantes a la hora de definir qué fenómenos pertenecen a esa categoría.

Por otro lado, el hecho de que el populismo incluya un componente normativo y específicamente peyorativo no es lo que es estudiado dentro de este artículo ni tampoco lo especial de este concepto. Lo significativo y lo que lo diferencia de otros conceptos esencialmente polémicos es que, de no ser por este componente normativo, el concepto de populismo generalmente podría confundirse sin incurrir en ningún error de definición (en términos clásicos) con el caudillismo o el paternalismo. Así, el núcleo del concepto es susceptible de ser confundido con otras categorías cercanas.

Esto es importante porque expone que no es posible reflejar la manera como el concepto se usa por medio de definiciones clásicas, pues es evidente que se usa desde un eje normativo. En este sentido, cualquier definición que pretenda bordear los límites conceptuales del populismo debe reconocer esa ambigüedad esencial del mismo. Su normatividad es el criterio exclusivo de cohesión de los diferentes casos que se rotulan como populistas. En consecuencia, si se evitara el componente normativo dentro de su caracterización, no quedaría ningún otro elemento restante que por sí mismo o en unión con otros bastara para explicar la categorización de los fenómenos dentro de esta categoría. Este rasgo del populismo es el que se presentó en este artículo.

Si el criterio para validar una definición de un concepto es que refleje la manera en que el concepto se usa en la práctica, entonces cualquier aproximación al populismo debe reconocer que dentro de la composición esencial del concepto existe una fuente de polémica inagotable que surge de la ambigüedad misma de los componentes connaturales al concepto. Aceptar ello efectivamente puede agravar los problemas para la categorización de los fenómenos como ejemplos de una categoría, pero ese es un problema que solo es importante si lo que se pretende lograr con las categorías es imponer límites estrictos que no son explicativos del uso del concepto.

\section{Conclusiones}

La categoría de concepto esencialmente polémico puede ser usada razonablemente para describir el estatus conceptual del populismo. Esto especialmente considerando la ausencia de un acuerdo doctrinal respecto de su significado y uso.

El estatus teórico del populismo como concepto esencialmente polémico obliga a que la composición misma de dicho concepto caiga en lugares comunes de polémica respecto de su correcto uso. Es por esto que se sostiene que dicha categoría solo tiene sentido desde un eje normativo, lo que también es la razón por la cual diferentes políticos carismáticos que son usuarios del lenguaje y los lugares discursivos comunes de la democracia son tildados de populistas, mientras otros que también lo hacen no lo son. La exigencia por una definición clásica de populismo es incoherente con la forma en que el concepto es utilizado, en tanto el populismo es un concepto con un núcleo normativo que define su uso. 


\section{Agradecimientos}

Agradezco a la Universidad EAFIT y, especialmente, por la asesoría para este artículo a Jorge Giraldo, Júlder Gómez y Nicolás Villegas.

\section{Referencias}

Antón, Antonio. (2015). Acerca del populismo: Polarización, hegemonía y ambigüedad ideológica. Madrid: Universidad Autónoma de Madrid.

Arditi, Benjamín. (2004). El populismo como espectro de la democracia: una respuesta a Canovan. Revista Mexicana de Ciencias Políticas y Sociales, 47(191), 86-99.

Arenas, Nelly. (2016). El chavismo sin Chávez: La deriva de un populismo sin carisma. Nueva Sociedad, 261, 13-22.

Berlin, Isaiah. (1978). Pensadores rusos. México: Fondo de Cultura Económica.

Bobbio, Norberto. (1982). Política. Diccionario de política. Ciudad de México: Siglo XXI.

Canovan, Margaret. (1981). Populism. Nueva York: Houghton Mifflin Harcourt P.

Cerutti, Horacio. (2009). Populismo. Ciudad de México: Universidad Nacional Autónoma de México. Instituto de investigaciones sociales.

Charaudeau, Patrick. (2009). Reflexiones para el análisis del discurso populista. Discurso \& Sociedad, 3(2), 253-279.

Connolly, William. (1993). The terms of political discourse. New Jersey: Princeton University Press.

De la Torre, Carlos. (2007). ¿Es el populismo la forma constitutiva de la democracia en Latinoamérica? En: Julio Aibar Gaete (Ed.). Vox Populi. Populismo y democracia en Latinoamérica. México: FLACSO.

De la Torre, Carlos. (2013). El populismo latinoamericano, entre la democratización y el autoritarismo. Nueva Sociedad, 247, 3-17.
Dornbusch, Rudi y Edwards, Sebastián. (1990). La Macroeconomía del populismo en América Latina. El Trimestre Económico, 57(225), 21-162.

Gallie, Walter. (1998). Conceptos esencialmente impugnados. Cuadernos de crítica, 49, 1- 42.

Gerring, John. (1997). Ideology: A definitional analysis. Political Research Quarterly, 50(4), 957-994.

Green, William. (2013). Gaitanismo, liberalismo de izquierda y movilización popular. Medellín: Fondo Editorial Universidad EAFIT.

Fairclough, I. y Fairclough, N. (2012). Political discourse analysis: A method for advanced students. London: Routledge.

Hermet, Guy. (2003). El populismo como concepto. Revista de Ciencia Política, 23(1), 5-18.

Kaiser, Axel y Álvarez, Gloria. (2016) El engaño populista. Por qué se arruinan nuestros países y cómo rescatarlos. Barcelona: Ediciones Deusto.

Laclau, Ernesto. (2005). La razón populista. Buenos Aires: Fondo de Cultura Económica.

Levitsky, Steven, y Loxton, James. (2013). Populism and competitive authoritarianism in the Andes. Democratization, 20(1), 107-136.

McRae, Donald. (1969). Populism as an ideology. En: Gellner, Ernesty lonescu, Ghita. (Eds), Populism. Its Meanings and National Characteristics. London: Weidenfeld and Nicolson.

Melo, Julián. (2014). Los tiempos del populismo. Devenir de una categoría polisémica. Colombia Internacional, 82, 71-98.

Mudde, Cas y Rovira, Cristóbal. (2017). Populism: A Very Short Introduction. Oxford: Oxford University Press.

Müller, Jan Werner. (2016). What Is Populism?Philadelphia: University of Pennsylvania Press.

Ortiz, Egda. (2009). Populismo y democracia en América Latina. Frónesis. 16(1), 43-62.

Palacios, Marco. (2011). Populistas: el poder de las palabras. Bogotá: Editorial Universidad Nacional de Colombia.

Pitkin, Hanna. (1972) The Concept of Representation. Los Angeles: University of California Press. 
Shils, Edward. (1956). The Torment of Secrecy: The Background and Consequences of American Security Policies. New York: Wiley

Vogel, Steffen. (2016). La tentación autoritaria: La nueva izquierda europea: entre el resurgimiento y el populismo. Nueva Sociedad, 261, 139-149.

Weyland, Kurt. (2001). Clarifying a contested concept: Populism in the study of Latin American politics. Comparative politics, 34(1), 1-22.

Wiles, Peter (1969) A syndrome not a doctrine: some elementary thesis on populism. En: Gellner, Ernest y Ionescu, Ghita. (Eds). Populism. Its Meanings and National Characteristics. London: Weidenfeld and Nicolson.
Wodak, Ruth. (2009). The Discourse of Politics in Action. London: Palgrave Macmillan.

Worsley, Peter. (1969). The concept of populism. En: Gellner, Ernest y lonescu, Ghita. (Eds), Populism. Its Meanings and National Characteristics. London: Weidenfeld and Nicolson.

Zaibert, Leo, y Smith, Barry. (2010). The Varieties of Normativity: An Essay on Social Ontology. En: Tsohatzidis, S. (Ed) Intentional Acts and Institutional Facts: Essays on John Searle's Social Ontology. Dordrecht: Springer.

Zanatta, Loris. (2014). Populismo. Buenos Aires: Katz. 